\title{
Vygotski e os conceitos científicos: implicações para a educação contemporânea ${ }^{1}$
}

\author{
Vygotski et les concepts scientifiques: implications pour l'éducation \\ contemporaine
}

Yuri V. Karpov²

A doutrina elaborada por Vygotski a propósito dos conceitos científicos, que são o conteúdo do ensino escolar, é produto direto de sua reflexão geral sobre a aprendizagem mediatizada, concebida como determinante essencial do desenvolvimento humano (ver Kozulin, no presente volume). Segundo Vygotski (1978, 1981, 1986), todos os processos mentais especificamente humanos (considerados como processos mentais superiores) passam pela mediação de ferramentas psicológicas como a linguagem, os signos e os símbolos. Foi a sociedade dos homens que inventou esses símbolos, e as crianças os adquirem no curso de sua comunicação interpessoal com os adultos e com seus pares mais experientes. Essas ferramentas, quando as crianças enfim as adquirem e as interiorizam, funcionam como mediadores de seus processos mentais superiores.

Vygotski considera o ensino escolar como a via principal de aprendizagem mediatizada. Para ele, é a escola que mais contribui para o desenvolvimento da criança durante o período da infância. Ele insiste, entretanto, no fato de que esses efeitos geradores de desenvolvimento só podem atingir o objetivo, na condição em que o processo de ensino seja organizado de maneira específica: "A única aprendizagem válida durante a infância é aquela que se antecipa ao desenvolvimento e o faz progredir. [...] Ela se apoia não só nas funções já amadurecidas, mas também naquelas em maturação." (Pensamento e linguagem,

\footnotetext{
${ }^{1}$ Tradução do capítulo 3 Vygotski et les concepts scientifiques: implications pour l'éducation contemporaine, publicado no livro Vygotski et l'éducation: apprentissages, développement et contextes culturels, sob direção de Alex Kozulin, Boris Gindis, Vladimir S. Ageyev, Suzanne M. Miller e tradução do inglês (publicado pela primeira vez em 2003) por Yves Bonin, publicado pela editora Retz, em 2009. A tradução publicada nesta revista se baseia prioritariamente na versão francesa, mas foram feitas consultas à versão em inglês, quando necessário. Convém destacar que há termos e conceitos não consensuais entre pesquisadores em relação ao pensamento de Vygotski. As referências no corpo do texto foram apresentadas como estavam na versão francesa. Além disso, foram acrescentadas as referências completadas no final do artigo como estavam na versão em inglês. (N.T).

${ }^{2}$ Graduado na Escola de Educação e Psicologia, Touro College, Nova York, Estados Unidos.
} 
tradução francesa, 1997, pp. 355-356.). Para Vygotski (1978, 1986), uma das razões essenciais do potencial desenvolvimental de um ensino escolar bem organizado é a de considerar a aquisição por parte da criança de "conceitos científicos", que podem se opor aos conceitos "espontâneos", que caracterizam as crianças em idade pré-escolar.

Os conceitos espontâneos resultam da generalização da experiência cotidiana na ausência do ensino sistemático. Eles são, por consequência, não sistemáticos, não conscientes e frequentemente equivocados. É assim que uma criança de 3 anos, após ter longamente observado o comportamento de uma agulha, de um alfinete ou de uma moeda mergulhados na água, vai tirar disso a conclusão errônea segundo a qual "todos os pequenos objetos afundam". Ela terá a tendência de generalizar esse "conceito" para predizer como diferentes objetos mergulhados na água também vão se comportar (Zaporozhets, 1986, p. 27). Se esses conceitos são efetivamente "não científicos" têm, no entanto, um papel importante na aprendizagem da criança, porque constituirão para ela as bases da aquisição dos conceitos científicos. Assim, por exemplo, "os conceitos históricos só podem começar a se desenvolver a partir do momento em que o conceito cotidiano [e espontâneo, Y. Karpov] de passado foi suficientemente distinguido" (Vygotski, 1986, p. 1940).

Os conceitos científicos, ao contrário dos conceitos espontâneos, representam a generalização da experiência da humanidade inteira, tal como ela se inscreve na ciência, no sentido mais amplo do termo, que engloba também as ciências naturais e sociais, as quais chamamos ciências humanas. Para retomar o exemplo proposto acima, o conceito científico que vai tornar possível uma predição do comportamento dos objetos mergulhados na água é o princípio de Arquimedes. Esses conceitos científicos são ensinados às crianças no conjunto do ensino sistemático que lhes é dispensado: elas os adquirem, então, conscientemente, e segundo um sistema bem preciso. Uma vez adquiridos, esses conceitos transformam os conhecimentos nascidos da experiência cotidiana: os conceitos espontâneos se estruturam e se tornam conscientes. A aquisição dos conceitos científicos constitui a "zona de desenvolvimento proximal" dos conceitos espontâneos (ver Chaiklin no presente volume para a análise do conceito vygotskiano de zona de desenvolvimento proximal).

A importância da aquisição de conhecimentos científicos não se limita ao 
fato de que eles "reestruturam e elevam os conceitos espontâneos a um nível superior" (Vygotski, 1987, p. 220). Uma vez que o aluno os adquiriu, esses conceitos científicos começam a agir como mediadores de seu pensamento e de sua maneira de resolver problemas. Essa é a razão pela qual "o ensino de conceitos científicos tem um papel decisivo no desenvolvimento mental da criança" (Vygotski, 1987, p. 220). Mais precisamente, "a consciência reflexiva vem à criança por intermédio dos conceitos científicos" (Vygotski, 1986, p.171). O pensamento da criança torna-se, desse modo, mais independente de sua experiência pessoal. Ela se torna mais “teórica” que "prática”, e é, então, capaz de operar no nível do pensamento lógico-formal.

Ao contrário dos conceitos construtivistas de Piaget (1970) e de Dewey (1902) (a respeito de quem falaremos mais à frente), Vygotski assegurou que não se deveria pedir às crianças para compreender o mundo, redescobrindo as principais leis explicativas que já teriam sido descobertas pela humanidade. Se o desenvolvimento dos pequenos humanos é tão particular, é porque os adultos lhes ensinam essas leis, porque a aquisição dos conceitos científicos deve resultar, segundo Vygotski, de sua apresentação aos alunos sob forma de definições verbais precisas (Vygotski, 1986, p.148).

Vygotski compreende muito claramente que "a dificuldade, com conceitos científicos, tem a ver com seu verbalismo" (1986, p. 148). Ele sublinha que o desenvolvimento dos "conceitos científicos [...] começa, bem antes de sua conclusão, no momento em que a criança apreende a palavra ou a significação da palavra que precisamente designa o novo conceito" (Vygotski, 1986, p. 159). Entretanto, ele não diz nada do que deveria ser o processo que permite o domínio dos conceitos científicos após terem sido apresentados ao aluno. Ele não fundamenta sua doutrina teórica referente ao papel desses conceitos na aprendizagem e no desenvolvimento das crianças em dados experimentais sólidos. Entretanto, as ideias que desenvolve a esse propósito constituem excelente base teórica para analisar o que deve ser o conteúdo, e o processo de ensino escolar que deveria atingir seus objetivos educativos. As seções seguintes serão dedicadas a essa análise. 


\section{O conteúdo do ensino: adquirir o saber científico}

Raros são os pesquisadores em ciências da educação que defendem atualmente a ideia segundo a qual o ensino poderia se reduzir à aquisição de conceitos científicos. Hirsch (1987) é um deles, autor o Programa de Cultura Geral ${ }^{3}$. Para ele, o conteúdo essencial do ensino escolar consiste em adquirir conceitos científicos e outras informações culturais verbais, como, por exemplo, nomes. Ele explica assim (1988): “As palavras nos remetem a coisas; conhecer muitas palavras é conhecer muitas coisas" (p. 24). Isso o levou a elaborar uma lista próxima de 5000 palavras que os alunos deviam memorizar durante sua escolaridade. Hirsch adota uma atitude mais radical que a de Vygotski que, como vimos, enfatiza a importância de aprender conceitos científicos, mas não de informações ou de conhecimentos verbais, e que está muito longe de preconizar que isso se realize pela via de uma memorização sem sentido.

Mesmo que ela não esteja muito na moda em pesquisas em educação, a ideia de que os alunos devem adquirir conceitos científicos, que é aqui um dos objetivos principais de ensino, não está menos presente implicitamente nos sistemas escolares atuais, por exemplo, nos Estados Unidos ou na Rússia. Professores tradicionais pedem muito frequentemente a seus alunos que memorizem regras, conceitos, definições e teoremas científicos.

Todavia, mostrou-se que a aquisição de um saber científico verbal não é suficiente para permitir aos alunos utilizar seus conhecimentos para resolver problemas nesta ou naquela disciplina. Davydov (1990) descreve assim os resultados de vários estudos feitos com alunos russos que ilustram perfeitamente esse ponto. É assim que depois de terem memorizado as características principais de mamíferos, de pássaros e de peixes, alunos do ensino primário a quem se pede que classifique os animais segundo essas categorias, se esforçam para responder à tarefa lançando mão de caraterísticas superficiais de animais que lhes são propostos, esquecendo-se completamente de recorrer aos conceitos memorizados (classificam, então, a baleia na categoria de peixes...). Em outro estudo, crianças do sexto ano memorizaram o conceito de triângulo retângulo. Mas sofrem para

\footnotetext{
${ }^{3}$ Programa de Alfabetização Cultural.
} 
reconhecer como triângulo retângulo aquele cujo ângulo reto se encontra no alto (trata-se para eles de um "triângulo de ângulo agudo"). Obtêm-se resultados similares em estudos com crianças americanas. Assim, um estudo nos mostra que o saber conceitual dos alunos em matéria de números não garante que possuam as competências necessárias para a resolução de operações de cálculo (Bruer, 1993).

Entretanto, a discussão precedente não visa a apoiar mais a ideia do ensino de conhecimentos procedimentais (as estratégias e as competências próprias das disciplinas), do que os conceitos científicos. Ao contrário, pesquisadores, tanto americanos quanto russos, estão convencidos de que um dos principais fracassos dos sistemas tradicionais de ensino de seus respectivos países se deve ao fato de que levam bem frequentemente os alunos a dominar procedimentos próprios para cada disciplina sem a aquisição do conhecimento conceitual de cada domínio. (Bruer, 1993; Davydov, 1990; Talyzina, 1981). Bruer (1993) tira a seguinte conclusão a propósito dos programas americanos tradicionais de ensino das matemáticas:

Numerosos são os alunos que não sabem como funcionam os procedimentos matemáticos que aprendem funcionalmente. Os alunos deixam a escola tendo as competências em cálculo para resolver problemas standard, mas lhes faltam a compreensão matemática de nível superior que lhes permitiria aplicar de modo amplo essas competências em situações novas. Muito frequentemente, os procedimentos de ensino das matemáticas produzem alunos que sabem manipular os símbolos numéricos, mas que não compreendem o que significam esses símbolos (p. 81).

Outros estudos, outras observações permitem verificar que os conhecimentos puramente procedimentais, em matemáticas ou em outras disciplinas, são desprovidos de sentido e não são transferíveis (Bruer, 1993; Davydov, 1990, Hiebert \& Wearne, 1985; Talyzina, 1981).

Para resumir, nem a aquisição de conceitos científicos, nem aqueles de conhecimentos procedimentais são suficientes para atingir os objetivos que o ensino deve cumprir. É, aliás, por essa razão, que os psicólogos americanos contemporâneos defendem a ideia de "casar conceitos com procedimentos" (Bruer, 1993, p.95), isto é, combinar esses dois tipos de conhecimentos ao longo do ensino.

Vygotskianos russos dos anos 30 chegaram à mesma conclusão (Leontiev, 
1983), e essas ideias, desde então, foram encontradas em numerosos estudos (Davydov, 1986,1990; Galperin, 1957, 1969; Galperin, Zaporozhets \& Elkonin, 1963; Talyzina, 1981). Adeptos e entusiastas da doutrina de Vygotski a respeito o papel dos conceitos científicos como mediadores essenciais do pensamento dos alunos e de sua maneira de resolver os problemas nas diferentes disciplinas, esses pesquisadores sublinharam, entretanto, que os conceitos científicos não desempenham plenamente seu papel de mediação senão quando são sustentados pelo domínio, por parte dos alunos, de procedimentos relevantes. Como diz Leontiev (1983), "para que uma criança desenvolva a generalização mais elevada [quer dizer, um conceito] é necessário desenvolver nela o sistema de operações psicológicas [os procedimentos Y. K.] que são relevantes para essa elevada generalização" (p. 347).

Os estudos de discípulos russos de Vygotski demonstraram que os procedimentos mais relevantes para formação de conceitos em determinado domínio são os métodos de análise científica próprios a esses domínios. É assim que os procedimentos que sustentam o princípio de Arquimedes são precisamente os métodos que permitem calcular a densidade dos objetos e comparar essas densidades com as da água. Vê-se igualmente que os procedimentos ligados ao conceito de retas perpendiculares são métodos que permitem identificar, entre os pares de retas dadas, os atributos necessários e suficientes para associar (ou não) esses pares de retas ao conceito de retas perpendiculares.

Combinados, conhecimentos conceituais e procedimentais são mais eficazes que o saber cientifico puramente verbal ou que procedimentos desprovidos de sentidos e não transferíveis, que são, frequentemente, resultado do ensino tradicional. O que caracteriza esses conhecimentos combinados, conceitos e procedimentos, é o nível elevado de domínio, uma larga capacidade de transferir e uma utilização intencional pelos estudantes. Eles são capazes de responder às questões do tipo "Por quê?", de dar importância ao modo como resolvem os problemas e defendem os resultados obtidos (Aidarova, 1978; Davydov, 1986, Elkonin \& Davydov, 1966; Galperin, 1985; Talyzina, 1981).

Assim, os trabalhos dos vigotskianos confirmaram a ideia cara a Vygotski, segundo a qual o saber científico é um mediador poderoso para o pensamento dos 
alunos em cada disciplina e para sua maneira de resolver problemas. Mas esse saber não pode se resumir somente às definições verbais de conceitos científicos: ele deve incluir também um saber procedimental importante para esses conceitos.

\section{A aprendizagem teórica como a via principal para a aquisição de conhecimentos científicos}

Qual professor, qual pesquisador em ciência da educação não se coloca a questão: “como ensinar?". Os métodos de ensino que adotam depende da resposta que dão a essa questão: aprendizagem pela descoberta, aprendizagem cooperativa, recursos as novas tecnologias, etc. E, entretanto, essa questão é absolutamente secundária para Vygotski e para aqueles que, na Rússia, seguiram seus passos. Para eles outra questão é posta: "quais conhecimentos nós queremos que as crianças adquiram?" (Elkonin, 1989).

Nós acabamos de ver que aqueles que seguiram o caminho aberto na Rússia por Vygotski aprofundaram seu ponto de vista concernente ao conteúdo do ensino e estão convencidos de que devia se tratar de conhecimentos científicos (isto é, a combinação de conceitos científicos e de procedimentos relevantes). Eles chegaram à conclusão de que o processo de aprendizagem só pode ser considerado como corretamente organizado se ele levar à aquisição de conhecimentos científicos.

Qual aprendizagem vai chegar a esse resultado? Para responder a essa questão, os pesquisadores impulsionaram a reflexão de Vygotski sobre a diferença entre conceitos espontâneos e conceitos científicos. Seus trabalhos mostraram que a aquisição dessas duas formas de conceitos resulta de tipos de aprendizagem fundamentalmente diferentes (Davydov, 1986, 1990; Galperin, 1985; Talyzina, 1981). Nós adotaremos a terminologia de Davydov, e nós qualificaremos de aprendizagem empírica aquela que resulta em conceitos espontâneos e de aprendizagem teórica aquela que resulta em conceitos científicos. A primeira se apoia nas comparações que fazem as crianças entre vários objetos ou eventos, quando percebem características evidentes comuns e formulam, a partir disso, um "conceito geral" concernente a esta classe de objetos ou de eventos. Essa estratégia pode perfeitamente funcionar por menor que as características salientes sejam efetivamente a expressão de características significativas, essenciais (é dessa maneira, por exemplo, que as crianças podem 
desenvolver o conceito vermelho de cor). Mas ela não funciona para um certo número de características comuns para várias espécimes de classe de objetos aos quais se relacionam; não são na verdade comuns a todos os objetos pertencentes a essa classe. É assim que se pode explicar o exemplo citado mais acima, em que as crianças da idade pré-escolar, que observaram uma agulha, um alfinete ou uma moeda afundarem quando mergulhados em água, concluem erroneamente que todos os "objetos pequenos afundam". Esses objetos têm em comum o fato de serem de pequeno tamanho, mas não é isso que caracteriza os objetos que afundam quando são mergulhados na água. Mais que isso, se as características comuns de objetos que lhes são submetidas são aquelas de todos os objetos pertencentes a uma classe dada, isso não é suficiente para que sejam expressas as características essenciais desses objetos. A cauda e as nadadeiras são características comuns aos peixes, mas não são características essenciais dessa espécie. É assim que os conceitos espontâneos desenvolvidos pela criança a propósito dos peixes ao final de uma aprendizagem empírica podem perfeitamente conduzir a uma concepção equivocada.

Concepções equivocadas são frequentes na aprendizagem empírica. Alunos americanos, como seus homólogos russos, manifestam numerosas concepções desse gênero (Davydov, 1990; DiSessa, 1982). Pode-se, razoavelmente, ver aqui o índice que a aprendizagem empírica frequentemente promove no sistema do ensino tradicional. Nós vimos que esse é um sistema no qual pede-se frequentemente aos alunos para aprender de cor, maquinalmente, as rotinas, ou definições científicas puramente verbais, mais do que lhes ensinar os conhecimentos científicos autênticos, em que se combinam conhecimentos conceituais e procedimentos próprios a uma disciplina dada (Bruer, 1993; Davydov, 1990). Em todos os casos, em que o aluno tenha adquirido uma habilidade rotineira ou aprendido a definição puramente verbal de um conceito científico, os conhecimentos assim adquiridos não podem ser aplicados de maneira flexível a fim de resolver problemas de uma dada disciplina: os conhecimentos decorados são desprovidos de sentido e não são transferíveis, já que os conhecimentos puramente verbais são perfeitamente inertes. Por essa razão, os alunos são levados a desenvolver seus próprios conceitos espontâneos e os procedimentos relevantes, para confrontar os problemas postos 
numa disciplina precisa.

É o que explica porque os alunos da escola primária podem memorizar os conceitos de mamíferos e de peixes, associando as baleias à classe de peixes, quando se trata de classificar diferentes tipos de animais nas espécies às quais pertencem. Pode-se pensar que não sendo capazes de utilizar as definições, simplesmente memorizadas desses conceitos científicos para resolver um problema próprio de uma disciplina, se envolvam num processo de aprendizagem empírica. Eles comparam os peixes "típicos", isolando os traços comuns, mais aparentes, e formulam a partir dessa base um conceito espontâneo de "peixe" que se releva errôneo. É provável que considerem para isso a forma do corpo, as nadadeiras ou as guelras, a cauda, e o fato de viver na água como critérios necessários e suficientes para pertencer à classe dos peixes. Seu conceito espontâneo de mamífero está todo equivocado. Quando se pede a eles para classificar os animais, recorrem às suas concepções falsas para orientar a sua análise, e as baleias são enquadradas na classe de peixes.

Parte-se dos procedimentos decorados e desprovidos de significação, que levam a conceitos espontâneos frequentemente equivocados. É o que se produz quando os alunos, após terem aprendido as operações de cálculo de maneira procedimental e rotineira, experimentam as piores dificuldades quando se trata de decidir qual operação deve ser aplicada para resolver um problema preciso. Para superar esta dificuldade,

Eles pesquisam uma palavra-chave que revelará qual operação deve ser utilizada, por exemplo, "tudo junto" ou "juntar" significa que precisa adicionar, "retirar" pede uma subtração, e "cada", uma multiplicação. Os alunos selecionam uma operação a partir de uma palavra-chave que procuram e aplicam cegamente, não importa qual seja o dado do problema, ou que isso tenha ou não um sentido. (Bruer, 1993, p.102).

A aprendizagem empírica não é nada além que o reflexo de tentativas do aluno de compensar as deficiências do sistema escolar tradicional, "descobrindo" por ele mesmo, conhecimentos científicos que não lhe foram ensinados na escola. Mas essas tentativas são, na essência, inúteis e levam ao desenvolvimento de conceitos espontâneos que não têm nada de científico. É por essa razão que aqueles que, na 
Rússia, seguiram a reflexão de Vygotski, segundo a qual o ensino dos conceitos científicos constitui o conteúdo da missão da escola, concluíram que esses conhecimentos científicos deveriam ser ensinados diretamente aos alunos, mais do que deixar a eles o cuidado de descobrir por eles mesmos. É o que chamaram aprendizagem teórica.

Aprendizagem teórica está baseada na aquisição pelo aluno de métodos de análise científica de objetos e de eventos próprios às diferentes disciplinas. Esses métodos consistem em selecionar as características principais desses objetos e eventos pertencentes a uma classe dada, e a apresentar essas características sob forma de modelos simbólicos e gráficos. Os professores ensinam os métodos de análise científica, que os alunos aprendem e interiorizam, no curso de sua utilização. Esses métodos são como ferramentas cognitivas com a ajuda dos quais os alunos podem resolver os problemas que lhes foram submetidos em sequência.

O programa Pantina (1957) é um excelente exemplo clássico de utilização de aprendizagem teórica. Ele foi concebido para ensinar às crianças de 6 anos a arte de escrever as letras do alfabeto russo. Nas classes tradicionais, envolvem-se os alunos em exercícios práticos. Aqui ensina-se aos alunos mais um procedimento útil para copiar cada contorno da letra. O professor explica que a essência de cada letra (mais geralmente de todo contorno) é seu modelo: é um conjunto de pontos, cada um representando um lugar onde se produz uma troca de direção no traçado. Copiar uma letra é, de início, construir seu modelo e isso passa pelas etapas seguintes: (a) analisa-se a letra a ser copiada para ter referência em quais lugares a direção do traçado muda; (b) coloca-se pontos nesses lugares precisos, e (c) se reproduz o mesmo sistema de pontos em outro lugar da página (isto é, construir o modelo de uma letra). Em seguida os alunos devem religar os pontos e voltam a escrever a letra pedida. No princípio, ensinase aos alunos a cumprir todas essas etapas no nível visual e motor, mas aos poucos eles dominam o procedimento, o essencial começa a se direcionar para o nível da imagem e do visual. Eles analisam visualmente a letra que deve ser copiada, construindo uma imagem mental do seu modelo, em seguida copiam a letra rapidamente e de maneira segura.

A utilização desse programa mostrou que o percurso dos alunos e os 
resultados de suas aprendizagens eram muito diferentes do que se pode observar numa classe "tradicional" (Pantina, 1957). Eles aprendem muito rápido e cometem poucos erros. O procedimento empregado é por sua vez significativo e facilmente transferível. Os alunos se acham capazes de utilizá-lo sozinhos para copiar não importa qual traço, que pode ser também aqueles de letras pertencentes aos alfabetos latino ou árabe, ou outra figura que não lhes é familiar. Os resultados obtidos graças a esse programa estão conformes a definição de conhecimentos científicos que, como vimos, deveriam ser o coração do ensino.

Pode-se mostrar que se obtém resultados todos também convincentes (nível elevado de apropriação dos conhecimentos adquiridos, transferência fácil e uso intencional pelos alunos) utilizando-se de outros programas de aprendizagem teórica. Programas desse tipo permitiram por mais de 30 anos a ensinar aos alunos, de todas as idades (de 5 anos até o primeiro ciclo universitário), temas bastante diversos: matemáticas elementares, álgebra, geometria, física, química, biologia, línguas vivas ou história. (Aidarova, 1978; Elkonin, 1976; Elkonin \& Davydov, 1966; Galperin, 1977, 1985; Galperin \& Talyzina, 1961, 1972; Salmina \& Sokhina, 1975; Venger, 1986; Zhurova, 1978, e outros). Uma pesquisadora americana, Schmittau, observou durante três anos alunos de classes elementares russas para os quais foram ensinadas as matemáticas utilizando esta abordagem de aprendizagem teórica. Ela revela que esses alunos:

Manifestam uma compreensão de matemáticas que não se encontra em geral em estudantes dos primeiros ciclos universitários ou faculdades americanas... [Ela] achou agradável ver a que ponto as crianças compreendem os conceitos matemáticos em seu nível mais abstrato e eram, por outro lado, capazes de generalizar situações novas que não lhes eram familiares. (Schmittau, 1993, p. 35).

Mais importante ainda, mostrou que a utilização sistemática de aprendizagem teórica facilitava o desenvolvimento cognitivo dos alunos. Essa forma de aprendizagem desenvolve em particular sua capacidade de trabalhar no nível do pensamento lógico-formal (Davydov, 1986,1990; Talyzina, 1981). Esses efeitos sobre o desenvolvimento confirmam largamente aquilo que tinha dito Vygotski (1986) (nós vimos anteriormente) quanto aos resultados de um ensino 
bem concebido (Arievitch \& Stetsenko, 2000, propõe uma revisão mais detalhada dos resultados de diferentes tipos de ensino em termos de desenvolvimento).

As ideias dos discípulos russos de Vygotski no que concerne às diferenças entre aprendizagem empírica e a aprendizagem teórica, e as vantagens da segunda, influenciaram diretamente os trabalhos de vários psicológicos americanos especializados em educação (Howe, 1996; Panofsky, John- Steiner \& Blackwell, 1992, Schmittau, 1993). Essas ideias estão, por outro lado, mais próximas daquelas formuladas recentemente por alguns psicólogos americanos que não são de inspiração vygotskiana, e que discutiram diferentes tipos de aprendizagem e transferência.

Bassok e Holyoak (1993) discutiram as transferências de tipo bottom-up ou top-down (descendente ou ascendente). O primeiro repousa na indução, partindo de exemplos: "integrando a informação tomada nos vários exemplos pertencendo a uma mesma categoria, as pessoas podem abstrair os componentes comuns a esses exemplos diferentes. As características que permanecem relativamente constantes de um exemplo a outro podem ser consideradas como pertinentes" ( $p$. 71). O inconveniente desse método é que ele "pode levar a aprendizagens equivocadas [ideias falsas. Y.K.] se certas características não pertinentes estiverem regularmente presentes nos diferentes exemplos." (Bassok \& Holyoak, 1993, p. 72). O outro tipo de transferência, o top-down, se apoia nos conhecimentos do aluno sobre a "pertinência pragmática", quer dizer, nas regras, nas leis e nos princípios que ele conhece e que regem um domínio dado; esse percurso "favorece uma transferência mais suave em direção aos problemas por vezes próximos e novos" (Bassok \& Holyoak, 1993, p. 72). No caso, quando esses conhecimentos não são instalados, "o professor (ou o texto) deve trazê-los diretamente para chamar a atenção do aluno para aspectos que convêm ao objetivo perseguido" (Bassok \& Holyoak, 1993, p. 73).

Alguns pesquisadores americanos expressaram pontos de vista similares. Detterman (1993) sublinha, por exemplo, a vantagem que se teria em fornecer aos alunos a regra geral desde o começo do ciclo do ensino, mais do que esperar que a deduzissem de exemplos que lhes são propostos. Referindo-se ao estudo dirigido por Bierdeman e Shiffar (1987), Anderson, Reder e Simon concluem que "20 minutos de ensino abstrato [trazendo as regras gerais, Y.K.] levam os alunos 
ao nível de experts que têm anos de prática.” (p. 8). A filosofia das ciências utiliza uma distinção do mesmo tipo, entre "simples generalização" (que "só correlaciona os fatos observáveis, empregando técnicas emprestadas das matemáticas") e "lei da natureza" ("que só se explica por noções tomadas no seu próprio campo disciplinar"). (Hanson, 1970, p. 235).

Seria, entretanto, abusivo pretender que a ideia de superioridade da aprendizagem teórica domine a psicologia americana. Muitos de seus membros professam uma outra perspectiva. É isso que nós vamos analisar agora.

\section{Aprendizagem pela descoberta guiada: ela permite adquirir conhecimentos científicos?}

A noção de aprendizagem empírica (ou de aprendizagem pela descoberta, como tem sido chamada na literatura psicológica americana) foi muito popular no meio de educadores americanos dos anos 60 e 70 (Morine \& Morine, 1973. E Shulman \& Keislar, 1966, propondo uma descrição e uma análise). Os resultados obtidos por esse método foram absolutamente conformes ao que tinham já dito os discípulos russos de Vygotski, e que nós acabamos de ver. Os conceitos espontâneos "descobertos" pelos alunos frequentemente eram ideias equivocadas (ver por exemplo Brown \& Campione, 1990). Anderson, Reder e Simon (1995) fazem o balanço das pesquisas, defendendo a aprendizagem pela descoberta; eles observam que "há poucas evidências positivas de aprendizagem por descoberta, e isso é frequentemente inferior" (p.13). Estas ideias, entretanto, ganharam novamente um recente interesse trazido pelos psicólogos da educação e por psicólogos cognitivistas americanos muito influentes (Brown \& Campione, 1990, 1994; Brown, Campione, Reeve, Ferrara \& Palincsarm 1991, Chang-Wells \& Wells, 1993; Cobb, Wood \& Yackel, 1993; Cobb, Yackel \& Wood, 1992; Grupo de Tecnologia e Cognição em Vanderbilt, 1990, 1992, 1994; Schoenfeld, 1985, 1992; Wells, Chang \& Maher, 1990). Esses pesquisadores não defendem a aprendizagem somente pela descoberta, da qual conhecem as insuficiências notórias, mas criticam vigorosamente o ensino tradicional. Segundo eles, esse último sofre de uma falha maior: os alunos não conseguem dominar os conhecimentos científicos, porque os conhecimentos lhes são trazidos por um professor e não são eles próprios que os descobrem. Eles se pronunciam por consequência "por um justo meio entre oensino 
didático e o ensino pela descoberta, sem nenhuma restrição: a descoberta guiada." (Brown \& Campione, 1994, p. 230).

Essa abordagem é largamente fundada em uma concepção construtivista da aprendizagem a partir dos trabalhos de Dewey (1902) e de Piaget (1970): os conhecimentos científicos não deviam ser ensinados aos alunos; eles mesmos deveriam construí-los ao longo de discussões, em que compartilhariam e confrontariam suas experiências pessoais, adquiridas no curso de um tipo de atividade de pesquisa. Um grupo de alunos que se beneficie de uma descoberta guiada seria parecido com um grupo de colaboradores pesquisando a solução de um problema científico (Cobb et al., 1992), em que o papel do professor é o de guiar e de orquestrar o processo de descoberta no qual estão implicados os alunos (Brown \& Campione, 1994).

Assim, diferentemente do que professam os discípulos de Vygotski, os parceiros da aprendizagem pela descoberta guiada consideram que o domínio dos conhecimentos científicos vem da elaboração e do aperfeiçoamento de conceitos espontâneos. Alguns desses autores estão claramente em oposição à importância dada por Vygotski às "definições formais e às explicações explicitas do professor", e preconizam de sua parte "a pesquisa matemática" que se "constrói de maneira interativa na classe" (Cobb et al., 1993, p. 100). Para validar a abordagem vygotskiana, é preciso testar a validade das posições teóricas de sessões de aprendizagem pela descoberta guiada, e analisar os resultados de sua utilização em um contexto de ensino.

Ora, os pressupostos teóricos dos adeptos dessa teoria são discutíveis. Para começar, o progresso humano só pode ocorrer quando cada nova geração se apropria da essência do conhecimento acumulado pelas gerações precedentes. Por que seria necessário esperar que nossos alunos reinventassem o saber, mesmo confiando ao professor o cuidado de "guiar" essa reinvenção? Como observou Bruner (1996), "A cultura [...] não é descoberta; ela é transmitida ou é esquecida" (p.101). Gagné (1966) é ainda mais explícito: "pedir a um indivíduo que se envolva em um procedimento fundamentado em ensaios e erros para descobrir um conceito é esperar que ele se comporte como um macaco" (p.143).

O segundo ponto é que a crítica ao sistema tradicional de ensino de sessões 
de aprendizagem feita pelos defensores da descoberta guiada, destinada a dar substância a essa abordagem, parece perder o ponto. Como foi demonstrado anteriormente, a deficiência da educação tradicional não é a de que os alunos necessitem de profundo conhecimento científico mais do que se envolverem nas descobertas, por eles mesmos, do conhecimento. Pelo contrário, esses estudantes estão ativamente envolvidos em tentativas malsucedidas de descobrir o conhecimento científico porque ele não lhes foi ensinado.

A terceira refutação que se pode endereçar àqueles que defendem a abordagem da descoberta guiada é que fazem frequentemente uma analogia entre um grupo de alunos engajados nesse trabalho e um grupo de pesquisadores resolvendo um problema científico. Essa analogia apresenta duas fragilidades. A primeira é que o processo pelo qual se resolve um problema científico pode durar anos, e que essa duração é incompatível com o currículo do ensino. A segunda é que a pesquisa cientifica utiliza métodos de pesquisa e de análise ensinados aos pesquisadores no âmbito de cursos universitários bem específicos, ou que desenvolveram no curso de sua experiência como pesquisadores. Não há nenhuma razão para que os alunos dominem esses métodos. Na verdade, nós vimos mais acima, o principal "método de pesquisa" que utilizam nessa situação quando são chamados a resolver um problema, sem dispor de conhecimentos científicos necessários, é o percurso empírico. Isto consiste em se apoiar nas características mais salientes de um fenômeno, mais que em suas características essenciais, e o resultado é frequentemente equivocado.

A quarta refutação é que o processo de elaboração e de aperfeiçoamento dos conceitos espontâneos para chegar aos conceitos científicos pelas vias da descoberta guiada é necessariamente um processo lento, procedendo por etapas. Mesmo nas condições mais favoráveis, implica que o aluno trabalhe a partir de seus conceitos espontâneos originais (que são frequentemente ideias equivocadas) durante todas as fases intermediárias de aprendizagem. Essa é provavelmente a razão pela qual os adeptos da aprendizagem pela descoberta guiada defendem com muito entusiasmo o direito ao erro dos alunos: "Enquanto você estiver em minha aula, você terá o direito de se enganar!" (Cobb et al.,1993, p.98). Alguns vão mesmo até declarar: "Nós consideramos particularmente aquilo que nossos 
alunos reconhecem que, na maior parte das decisões, não há o que é certo de um lado e o que é falso de outro" (Heller \& Gordon, 1992, p.10). Pode-se aliás considerar uma objeção teórica a essa atitude "relaxada" diante de conhecimentos científicos: como isso poderia contribuir para fazê-los compreender o valor de adquirir esse conhecimentos?

Em suma, mesmo se essa aprendizagem for guiada por um professor, persiste o perigo de que ela acabe em ideias equivocadas. Como observaram Brown e Campione (1994), a descoberta guiada é bem difícil de ser colocada em prática. Ela implica, com efeito, inúmeras atividades não guiadas quando, por exemplo, os alunos se comportam como um grupo de pesquisadores trabalhando em um projeto. Chang-Wells e Wells (1993) dizem claramente: "Uma boa parte da aprendizagem se produz quando os alunos trabalham juntos de maneira (mais ou menos) colaborativa, sem que o professor tome parte dela" (p. 84). Dados experimentais mostram que quando um grupo de pares trabalha nessas condições, não é raro que acabem por rejeitar um conceito correto por um outro absolutamente errado, formulado por um dos participantes (Tudge, 1992). Todas as hipóteses teóricas de aprendizagem pela descoberta guiada são discutíveis. Mas é bem evidente que o que conta antes de tudo é a análise dos resultados obtidos por essa maneira de ensinar. Se os adeptos acreditam nisso, seria benéfico. As relações mostram que com os alunos que adquirem e transferem melhor seus conhecimentos, a planificação e o controle de suas atividades melhoram, sua motivação é superior ao que ela era no sistema tradicional (Brown \& Campione, 1994; Change-Wells \& Wells, 1993; Cobb et al., 1991; Cognition-and Technology Group at Vanderbilt, 1994; Schoenfeld, 1992). Mas Anderson, Reder e Simon (1995) observam que os construtivistas têm sempre um problema quando se trata de avaliar os resultados de seus métodos de ensino: "Eles não conseguem precisar a competência testada, e sustentam sobretudo sua confiança em julgamentos subjetivos" (p.18). Naquilo que se segue, eu gostaria de trazer julgamentos pessoais a respeito de dois resultados obtidos pela utilização da aprendizagem por descoberta guiada, para saber se este procedimento permitiu, ou não, aos alunos adquirir conhecimentos científicos. É importante notar que esses dois exemplos foram citados pelos adeptos deste método para provar que ele apresenta vantagens. 
Heller e Gordon (1992), que trabalharam no projeto de Brown e Campione (1994), descrevem uma lição por descoberta guiada na qual o projeto é fazer que os alunos adquiram o conceito de animal. A maior parte da lição consistiu em uma discussão bastante longa durante a qual os alunos trocaram seus conceitos espontâneos a respeito desse tema. Então, um aluno pega um dicionário e lê a definição científica do que é um animal. Para os autores, essa lição é um sucesso: os alunos se envolveram na discussão, permaneceram bem focados no tema, pediram esclarecimentos quando era preciso, e obtiveram comentários e explicações de seus colegas de classe. No entanto, dois pontos merecem ser sublinhados. O primeiro é que as crianças obtiveram o conceito científico de animal do dicionário; não o descobriram por eles mesmos a partir da elaboração de seus conceitos espontâneos. O segundo é que nada indica que a aprendizagem também atinja um domínio de conhecimentos procedimentais pertencentes a este conceito. $\mathrm{O}$ caso que nos interessa consistiria em um método que permitisse identificar num objeto proposto os atributos necessários e suficientes para associar (ou não) este objeto com o conceito de animal.

O segundo exemplo traz a utilização de um CSILE (Computer Supported International Learning Environment), quer dizer, um meio de aprendizagem intencional assistido pelo computador (encontra-se uma descrição em Bruer, 1993, pp. 250-256). Esse programa se baseia abertamente em princípios construtivistas de aprendizagem pela descoberta guiada e utiliza generosamente a tecnologia da informática moderna. Os alunos trocam por exemplo e-mails, e criam juntos uma base de dados relativa ao programa. Bruer (1993) nota que o resultado principal desse programa é que os alunos escrevem melhor. Ele destaca em particular que "quando dão por escrito uma resposta à questão "o que eu aprendi seguindo essa seção?”, os alunos que seguiram um CSILE redigem ensaios bem construídos, que contêm certas convenções textuais bem elaboradas, já os alunos que progrediram no sistema tradicional se contentam com narrativas um pouco simplistas" (p. 253). $\mathrm{Na}$ medida em que "uma aprendizagem melhor e um melhor raciocínio [...] levam a uma escrita melhorada” (Bruer, 1993, p. 251), o autor quer aqui ver a prova do sucesso desse programa CSILE.

Para ilustrar os benefícios do programa, Bruer compara parágrafos 
extraídos de dois ensaios respondendo à seguinte questão "o que eu aprendi sobre o tema dos primatas". O primeiro é de uma criança que se beneficiou do programa CSILE, o segundo de um aluno que não se beneficiou dele. Eu somente citarei aqui as três primeiras e as três últimas frases dos dois excertos. $\mathrm{O}$ aluno que seguiu um programa tradicional escreve:

Eu sei o essencial sobre os gorilas, é por isso que é por eles que começarei. Há vários tipos de gorilas. Por exemplo, os gorilas da montanha têm uma pelagem mais bonita e mais brilhante que aqueles das planícies... As costas prateadas: o dominante tem direitos de reprodução exclusivos. O bebê vai dormir num abrigo noturno com sua mãe até que sua mãe tenha outro bebê, o que não acontecerá antes que o primeiro bebê atinja a idade de 4 a 5 anos. Um abrigo noturno é um grande abrigo feito de todos os tipos de grandes plantas. (Bruer,1993, p. 254).

A criança CSILE, escreve:

Há outro primata do qual eu quero falar. Eu experimentei um grande interesse para aprender coisas sobre esse grande gorila muito especial. Seu nome é Koko... eu penso que Koko é um gorila caloroso e gentil que ama os animais e as pessoas. Eu quero também agradecer o Dr Patterson que tudo nos ensinou sobre Koko. $\mathrm{Eu}$ estou feliz de ter seguido esse programa porque eu experimentei um grande prazer ao fazê-lo e eu tenho agora a impressão que eu conheço pessoalmente Koko. (Bruer, 1993, p. 254).

Para detalhar seu ponto de vista, segundo qual o parágrafo escrito pelo aluno CSILE é superior ao outro, Bruer insiste no fato de que "juízes independentes dão invariavelmente notas superiores aos ensaios terminados no fim da sessão pelos alunos CSILE em relação àqueles produzidos pelos alunos não CSILE, no que concerne à qualidade dos conhecimentos expressos e à qualidade da expressão e da apresentação" (pp. 253-254).

A avaliação desses dois parágrafos de Bruer pode parecer muito discutível. Esses parágrafos, para começar, não permitem avaliar o saber procedimental dos alunos, quer dizer, sua capacidade de resolver problemas ligados ao problema abordado. O que nos é proposto só permite avaliar seus conhecimentos declarativos. Minha segunda objeção é que, mesmo desse ponto de vista, aquele dos conhecimentos declarativos, a posição de Bruer é contestável. Nestes sete últimos anos, eu submeti esses parágrafos a várias centenas de meus estudantes, cuja 
maior parte era de professores já muito experientes. Eu lhes propus avaliá-los e as reações foram muito significativamente diferentes da avaliação de Bruer. Eles foram tocados pelo caráter muito egocêntrico do aluno do CSILE (diferentemente de seu semelhante não pertencente ao CSILE); eles o consideraram como muito imaturo e estimaram que não respondeu ao tema proposto para o ensaio. $\mathrm{O}$ aluno não pertencente ao CSILE expôs seus conhecimentos conceituais nesse domínio e nos diz o que ele sabe das características gerais dos gorilas; o aluno do CSILE exprime suas emoções a respeito de Koko e somente apresenta alguns raros fatos relativos a esse único gorila em particular. Alguns de meus estudantes deduziram que o aluno CSILE deveria ser bem mais jovem que o outro. Meus colegas (psicólogos, linguistas e educadores) da Graduate School of Education and Psychology du Collège Touro avaliaram esses parágrafos de maneira muito parecida. Esses exemplos de resultados obtidos pelo percurso da aprendizagem da descoberta guiada, mas também os problemas teóricos expostos mais acima, permitem duvidar que esse percurso seja adaptado ao ensino dos conhecimentos científicos. Essa conclusão se junta à apreciação geral de Anderson, Reder e Simon (1995) para quem "o construtivismo preconiza uma aprendizagem e procedimentos de avaliação muito ineficazes" (p. 1).

\section{Conclusão}

A doutrina de Vygotski, segundo a qual os conceitos científicos constituem o conteúdo do ensino, não está livre de fracassos. O mais sério é que ele subestima gravemente a aquisição de conhecimentos procedimentais. Mas ela foi utilizada por todos aqueles que, na Rússia, seguiram Vygotski nessa via, e que dela fizeram a base teórica de sua análise do que devem ser o conteúdo e os processos de ensino, se se deseja atender aos seus objetivos.

Após ter aprofundado e aperfeiçoado as ideias de Vygotski, seus discípulos russos chegaram à conclusão de que o ensino deve ser construído em torno de conhecimentos científicos, os quais consistem em métodos de análise científica próprios a diferentes domínios do conhecimento. Pôde-se demonstrar que o ensino realizado pela escola tradicional não satisfaz a essa exigência. Acontece frequentemente de não ensinar os conhecimentos científicos aos alunos. Face aos 
problemas que lhe são propostos por uma disciplina dada, são obrigados a recorrer à aprendizagem empírica para desenvolver seus conceitos espontâneos. A alternativa que lhes propõem os discípulos russos de Vygotski é aquela da aprendizagem teórica, construída em torno de suas concepções do conteúdo e dos processos de ensino. Demonstrou-se que os programas concebidos, segundo este percurso, levaram os alunos aos conhecimentos científicos, às vezes significantes e facilmente transferíveis, que são capazes de aplicar a análise de fenômenos tratados em certas disciplinas. Graças a essa abordagem, "a criança, como aprendiz independente, é considerada mais como um resultado que como uma premissa do processo de aprendizagem" (Kozullin, 1995, p. 121).

Aqueles que, nos Estados Unidos, são adeptos da aprendizagem por descoberta guiada, defendem um ponto de vista oposto àquele do ensino tradicional, e propõem um meio para superar as deficiências. Fortemente influenciados pelas ideias construtivistas, estimam que se os alunos não dominam os conhecimentos científicos, é porque foram ensinados, e que eles próprios não os descobriram. Os programas que conceberam propõem uma aprendizagem empírica que, segundo os vygotskianos russos, agravam mais do que superam as falhas do ensino tradicional. Os resultados obtidos pela descoberta guiada, e que nós discutimos nesse capítulo, desafiam seus adeptos, que afirmam ser esse o método que leva à aquisição de conhecimentos científicos.

Prawat (1995) diz claramente: duas reformas do ensino americano, articuladas em torno dos princípios construtivistas, fracassaram sucessivamente. Se se acredita no que acabamos de ver, a terceira onda de reforma construtivista, que se funda na aprendizagem pela descoberta guiada, não é muito promissora. É razoável atribuir isso às falhas do construtivismo como teoria de aprendizagem. Em oposição, a doutrina vygotskiana dos conceitos científicos demonstrou que ela era uma ferramenta poderosa para analisar as abordagens atuais do ensino e para desenvolver novas abordagens. É mais um exemplo do fato de que as ideias de Vigotski, formuladas nos anos 30, continuam surpreendentemente atuais. 


\section{Referências}

Aidarova, L. I. (1978). Psikhologicheskie problemy obucheniya mladshikh shkolnikov russkomu yazyku [Psychological problems of teaching Russian language to elementary-school pupils]. Moscow: Prosveschenie.

Anderson, J. R., Reder, L. M., \& Simon, H. A. (1995). Applications and misapplications of cognitive psychology to mathematics education. Available at: http://www.psy.cmu.edu/ mm4b/misapplied.html

Arievitch, I. M., \& Stetsenko, A. (2000). The quality of cultural tools and cognitive development: Gal'perin's perspective and its implications. Human Development, 43, 69-92. https://doi.org/10.1159/000022661.

Bassok, M., \& Holyoak, K. J. (1993). Pragmatic knowledge and conceptual structure: Determinants of transfer between quantitative domains.In D. K. Detterman \& R. J. Sternberg (Eds.), Transfer on trial: Intelligence, cognition, and instruction (pp. 68-98). Norwood, NJ: Ablex.

Biederman, I., \& Shiffrar, M. (1987). Sexing day-old chicks: A case study and expert systems analysis of a difficult perceptual learning task. Journal of Experimental Psychology: Learning, Memory, and Cognition, 13, 640-645. https://doi.org/10.1037/0278-7393.13.4.640

Brown, A. L., \& Campione, J. C. (1990). Communities of learning and thinking: or a context by any other name. Contributions to Human Development, 21, 108126. https://doi.org/10.1159/000418984

Brown, A. L., \& Campione, J. C. (1994). Guided Discovery in a community of learners. In K.McGilly (Ed.), Classroom lessons: Integrating cognitive the oryand classroom practice (pp. 229-270). Cambridge, MA: MIT Press.

Brown, A. L., Campione, J. C., Reeve, R. A., Ferrara, R. A., \& Palincsar, A. S. (1991). Interactive learning and individual understanding: The case of reading and mathematics. In L. T. Landsman (Ed.), Culture, schooling, and psychological development (pp. 136-170). Hillsdale, NJ: Erlbaum.

Bruer, J. T. (1993). Schools for thought: A science of learning in the classroom. Cambridge, MA: MIT Press.

Bruner, J. S. (1966). Some elements of discovery. In L. S. Shulman \& E. R. Keislar (Eds.), Learning by discovery: A critical appraisal (pp. 101-113). Chicago: Rand McNally.

Chang-Wells, G. L. M., \& Wells, G. (1993). Dynamics of discourse: Literacy and the construction of knowledge. In E. A. Forman, N. Minick, \& C. A. Stone (Eds.), 
Contexts for learning: Sociocultural dynamics in children's development (pp. 5890). New York: Oxford University Press.

Cobb, P., Wood, T., \& Yackel, E. (1993). Discourse, mathematical thinking, and classroom practice. In E.A.Forman, N. Minick, \& C. A. Stone (Eds.), Contexts for learning: Sociocultural dynamics in children's development (pp. 91-120). New York: Oxford University Press.

Cobb, P., Wood, T., Yackel, E., Nicholls, J., Wheatley, G., Trigatti, B., \& Perlwitz, M. Assessment of a problem-centered second grade mathematics project. Journal for Research in Mathematics Education, 22, 3-29. https://doi.org/10.2307/749551

Cobb, P., Yackel, E., \& Wood, T. (1992). A constructivist alternative to there presentational view of mind in mathematics education. Journal for Research in Mathematics Education, 23, 2-33. https://oi.org/10.2307/749161

Cognition and Technology Group at Vanderbilt. (1990). Anchored instruction and its relationship to situated cognition. Educational Researcher, 19(6), 2-10. https://doi.org/10.3102/0013189x019006002

Cognition and Technology Group at Vanderbilt. (1992). The Jasper experiment: An exploration of issues in learning and instructional design. Educational Technology Research and Development, 40, 65-80. https://doi.org/10.1007/bf02296707

Cognition and Technology Group at Vanderbilt. (1994). From visual word problems to learning communities: Changing conceptions of cognitive research. In K. McGilly (Ed.), Classroom lessons: Integrating cognitive theory and classroom practice (pp. 157-200). Cambridge, MA: MIT Press.

Davydov, V. V. (1986). Problemy razvivayuschego obucheniya [Problems of development-generating learning]. Moscow: Pedagogika.

Davydov, V. V. (1990). Types of generalization in instruction. Reston, VA: National Council of Teachers of Mathematics.

Detterman, D. K. (1993). The case for the prosecution: Transfer as an epiphenomenon. In D. K. Detterman \& R. J. Sternberg (Eds.), Transfer on trial: Intelligence, Cognition, and Instruction (pp. 1-24). Norwood, NJ: Ablex.

Dewey, J. (1902).The child and the curriculum. Chicago: University of Chicago Press. DiSessa, A. A. (1982). Unlearning Aristotelian physics: A study of knowledgebased learning. Cognitive Science, 6, 37-75. https://doi.org/10.1016/s0364$\underline{0213(82) 80005-0}$

Elkonin, D. B. (1976). Kak uchit detei chitat [How to teach children to read]. Moscow: Znanie. 
Elkonin, D. B. (1989). Izbrannye psikhologicheskie trudy [Selected psychological works]. Moscow: Pedagogika.

Elkonin, D. B., \& Davydov, V. V. (Eds.) (1966). Vozrastnye vozmozhnosti usvoeniya znanii [Age-dependent potentialities of acquiring knowledge]. Moscow: Prosveschenie.

Gagné, R. M. (1966). Varieties of learning and the concept of discovery. In L. S. Shulman \& E.R.Keislar (Eds.), Learning by discovery: A critical appraisal (pp.135-150). Chicago: Rand McNally.

Galperin, P. Y. (1957). Umstvennoe deistviye kak osnova formirovaniya mysli i obraza [Mental act as the basis for formation of thought and image]. Voprosy Psikhologii, 6, 58-69.

Galperin, P. Y. (1969). Stages in the development of mental acts. In M. Cole \& I. Maltzman (Eds.), A handbook of contemporary Soviet psychology (pp. 34-61). New York: Basic Books.

Galperin, P. Y. (Ed.) (1977). Upravlyaemoe formirovanie psikhicheskikh protsessov [Guided formation of the mental processes]. Moscow: Izdatelstvo MGU.

Galperin, P. Y. (1985). Metody obucheniya i umstvennoe razvitie rebenka [Methods of instruction and the child's mental development]. Moscow: Izdatelstvo MGU.

Galperin, P. Y., \& Talyzina, N. F. (1961). Formation of elementary geometrical concepts and their dependence on directed participation by the pupils. In $\mathrm{N}$. O'Connor (Ed.), Recent Soviet psychology (pp. 247-272). New York: Liveright. https://doi.org/10.1016/b978-0-08-009575-2.50017-2

Galperin,P. Y., \& Talyzina, N. F. (Eds.) (1972). Upravlenie poznavatelnoi deyatelnostyu uchaschikhsya [Guidance of cognitive activity of students]. Moscow: Izdatelstvo MGU.

Galperin, P. Y., Zaporozhets, A. V., \& Elkonin, D. B. (1963). Problemyformirovaniya znanii i umenii u shkolnikov i novye metody obucheniya $\mathrm{v}$ shkole [The problems of formation of knowledge and skills in school-children and the new methods of instruction at school]. Voprosy Psikhologii, 5, 61-72.

Hanson, N. R. (1970). A picture theory of theory meaning. In R. G. Colodny (Ed.), The nature and function of scientific theories (pp. 233-273). Pittsburgh: University of Pittsburgh Press.

Heller, J. I., \& Gordon, A. (1992). Lifelong learning. Educator, 6(1), 4-19. 
Hiebert, J., \& Wearne, D. (1985). A model of students'decimal computation procedures. Cognition and Instruction, 2, 175-205. https://doi.org/10.1080/07370008.1985.9648916

Hirsch, E. D. (1987). Cultural literacy. New York: Vintage Books.

Hirsch, E. D. (1988, July/August). A postscript by E. D. Hirsch. Change, 22-26.

Howe, A. C. (1996). Development of science concepts within a Vygotskian framework. Science Education, 80(1), 35-51.

Kozulin, A. (1995). The learning process: Vygotsky's theory in the mirror of its interpretations. School Psychology International, 16, 117-129.

Leontiev, A. N. (1983). Ovladenie uchaschimisyan auchnymi poniatiyami kak problema pedagogiches koi psikhologii [Mastering scientific concepts by students as a problem of educational psychology].In A. N. Leontiev, Izbrannye psikhologicheskie proizvedeniya (Tom 1, pp. 324-347). Moscow: Pedagogika.

Morine, H., \& Morine, G. (1973). Discovery: A challenge to teachers. Englewood Cliffs, NJ: Prentice-Hall.

Panofsky, C. P., John-Steiner, V., \& Blackwell, P. J.(1992). The development of scientific concepts and discourse. In L. C. Moll (Ed.), Vygotsky and education: Instructional implications of sociohistorical psychology. Cambridge: CambridgeUniversity Press. https://doi.org/10.1017/cbo9781139173674.012

Pantina, N. S. (1957). Formirovanie dvigatelnogo navyka pisma v zavisimosti ottipa orientirovki v zadanii [Formation of writing skills depending on the type of task orientation]. Voprosy Psikhologii, 4, 117-132.

Piaget, J. (1970). Genetic epistemology. New York: Columbia University Press. Prawat, R. S. (1995). Misreading Dewey: Reform, projects, and the language game. Educational Researcher, 24(7), 13-22. https://doi.org/10.3102/0013189x024007013

Salmina, N. G., \& Sokhina, V. P. (1975). Obuchenie matematike v nachalnoi shkole [Teaching mathematics in elementary school]. Moscow: Pedagogika.

Schmittau, J. (1993). Vygotskian scientific concepts: Implications for mathematics education. Focus on Learning Problems in Mathematics, 15(2, 3), 29-39.

Schoenfeld, A. H.(1985). Mathematical problem solving. NewYork: AcademicPress. 
Schoenfeld, A. H. (1992). Learning to think mathematically: Problem solving, metacognition, and sense making in mathematics. In P. H. Grouws (Ed.), Handbook of research on mathematics teaching: A project of the National Council of Teachers of Mathematics (pp. 334-370). New York: MacMillan. https://doi.org/10.1177/002205741619600202

Shulman, L. S., \& Keislar, E. R. (Eds.) (1966). Learning by discovery: A critical appraisal. Chicago: Rand McNally.

Talyzina, N. F. (1981). The psychology of learning. Moscow: Progress.

Tudge, J. (1992). Vygotsky, the zone of proximal development, and peer collaboration: Implications for classroom practice. In L. C. Moll (Ed.), Vygotsky and education: Instructional implications and applications of sociohistorical psychology (pp. 155-172). Cambridge: Cambridge University Press. https://doi.org/10.1017/cbo9781139173674.008

Venger, L. A. (Ed.) (1986). Razvitie poznavatelnykh sposobnostei v protsesse doshkolnogo vospitaniya [Development of cognitive abilities in the course of preschool education]. Moscow: Pedagogika.

Vygotsky, L. S. (1978). M. Cole, V. John-Steiner, S. Scribner \& E. Souberman (Eds.), Mind in society: The development of higher psychological processes. Cambridge, MA: Harvard University Press. https://doi.org/10.2307/j.ctvjf9vz4

Vygotsky, L. S. (1981). The genesis of higher mental functions. In J.V.Wertsch(Ed.), The concept of activity in Soviet psychology (pp. 144-188). Armonk, NY: Sharpe. Vygotsky, L. S. (1986). Thought and language. Cambridge, MA: MIT Press.

Vygotsky, L. S. (1987). R. W. Rieber(Ed.), The collected Works of L. S. Vygotsky.Vol.1. Problems of general psychology. New York: Plenum.

Wells, G., Chang, G. L., \& Maher, A. (1990). Creating classroom communities of literate thinkers. In S. Sharan (Ed.), Cooperative learning: Theory and research (pp. 95-121). New York: Praeger.

Zaporozhets, A. V. (1986). Razvitie myshleniya [The development of thinking]. In A. V. Zaporozhets, Izbrannye psikhologicheskie trudy, Tom1(pp.200-215). Moscow: Pedagogika.

Zhurova, L. E. (1978). Obuchenie gramote v detskom sadu [Teaching reading and writing at the kindergarten]. Moscow: Pedagogika.

Tradução e revisão: Adriana Pastorello Buim Arena

Dagoberto Buim Arena

Recebido em novembro de 2018. Aprovado em abril de 2019. 